\title{
Comparative Study of Factors and Problems Affecting Ability of Undergraduate Students at RMUTL Tak to Read English Language Journals
}

\author{
Sathirasak Rungsinanont \\ English for International Communication Program, Rajamangala University of Technology Lanna Tak, \\ Thailand. \\ Email:sathirasak@gmail.com Tel: +66952945452
}

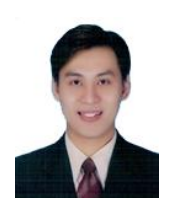

\begin{abstract}
The objectives of the study are to investigate the most significant contributory factors affecting Engineering students' reading ability in regard to journals, and to identify the problems thus encountered when they read English language journals. The participants in this study consisted of 60 Engineering students who were majoring in Industrial Engineering and Electrical Engineering. The research tool was a questionnaire that consisted of three parts: (1) general information, (2) factors that affect the ability to read English language journals, and (3) the problems that occur during reading of English language journals. The results of the study indicate that the outstanding contributory factors affecting students' reading ability of English journals are anxiety $(\bar{x}=4.90)$ and knowledge of vocabulary $(\bar{x}=4.77)$, significant at the level of 0.05 . The problems they encounter in reading English journals include the following: the vocabulary is difficult; unable to translate; too lazy to read; misunderstanding the content; journals are difficult; journals have too many pages; and students not interested in reading. Over a range of problems, a common factor was that the content was not related to what they had previously learned.
\end{abstract}

Keywords: Contributory factors, Anxiety, Knowledge of vocabulary, Reading problems, Reading ability, English journals, Undergraduate students.

Citation | Sathirasak Rungsinanont (2020). Comparative Study of Factors and Problems Affecting Ability of Undergraduate Students at RMUTL Tak to Read English Language Journals. Journal of Education and e-Learning Research, 7(4): 446-455.

History:

Received: 24 August 2020

Revised: 5 October 2020

Accepted: 13 November 2020

Published: 30 November 2020

Licensed: This work is licensed under a Creative Commons

Attribution 3.0 License (cc)

Publisher: Asian Online Journal Publishing Group
Acknowledgement: Aurhor would like to thank the Industrial and Electrical Engineering students at Rajamangala University of Technology who participated and provided valuable information in this study; additionally, participated and provided valuable information in this study; additionally,
Author's friends both inside and outside the English for International Communication Program during this study. Lastly, author would like to thank them all wholeheartedly for their support

Funding: This study received no specific financial support.

Competing Interests: The author declares that there are no conflicts of interests regarding the publication of this paper. Transparency: The author confirms that the manuscript is an honest, accurate, and transparent account of the study that was reported; that no vital features of the study have been omitted; and that any discrepancies from the study as planned have been explained.

Ethical: This study follows all ethical practices during writing.

\section{Contents}

1. Introduction

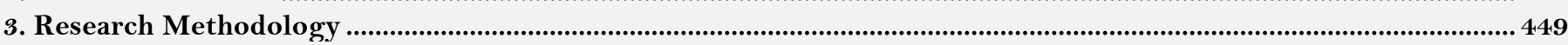

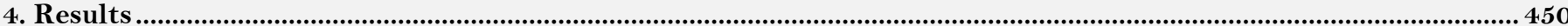

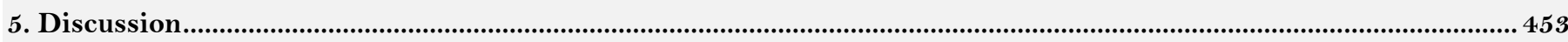

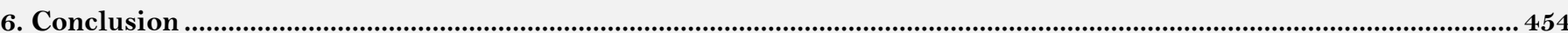

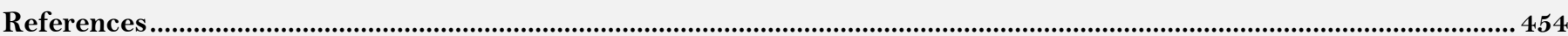




\section{Contribution of this paper to the literature}

This study contributes to existing literature by examining the most significant contributory factors affecting ability of Engineering students' at RMUTL Tak to read English language journals and investigating problems with the reading ability of students at RMUTL Tak. Additionally, this study will be expected very useful for the improvement of learning and teaching reading ability especially improving Thai EFL students' reading English journals ability by applying the appropriate reading materials, pedagogy and classroom management which may be helpful for enhancing the reading skill regarding their graduating and for their future careers.

\section{Introduction}

It is often said that English is the foreign language most commonly used throughout the world. People from different nationalities want to communicate with others using English, and that is why English is called "the language of communication". However, the major goal of English language learning and teaching should be to provide learners with the ability to use English effectively, with particular accuracy in communication (Davies \& Pearse, 2000). According to the Common European Framework, English skills are divided into productive and receptive. Productive skills consist of speaking and writing and they are significant because they permit learners to perform in communicative aspects such as oral presentations, written studies, and reports among others. Receptive skills comprise reading and listening, and are important because they allow learners to understand contents, textbooks, works, or documents. Therefore, these skills need to be developed and learned properly. Reading seems to be the most important among the four skills (Ur, 1996).

Presently, reading plays a significant role for learners. It is important for their learning and they gain knowledge from it for their future life - for example, for further study or business. Reading is a more important skill for students learning English around the world than other skills, especially in Thailand, where students who are learning English as a foreign language means that they use English only in the classroom, with most classes taught using Thai for understanding. Therefore they have little chance to speak English and when they graduate they do not meet foreigners but they can read books written in English (Hayikaleng, Nair, \& Krishnasamy, 2016). Reading, as part of second-language (L2) literacy instruction, has become the main focus of teaching English to children for two main reasons: (1) English language teaching has become mandatory from a young age throughout the world (Ediger, 2001; Enever, 2009; Enever. \& Moon, 2009); and (2) reading is regarded as "one of the most important skills in academic settings" for L2 learners (Grabe, 2002).

As mentioned above, it has been revealed that reading is recognized as a necessary and highly significant skill (Mingsakoon, 2003 as cited in Wutthisingchai and Stopps (2018)) for modern life. In Thailand, although English is not an official language for communication in daily life for students, according to educational variation, engineering students in particular who study in rural areas at the undergraduate level and have low reading skills must study and read journals in English to obtain the necessary knowledge. Thai students learn and use English as a foreign language, which is mostly used for learning and teaching in the classroom. As a result of this, students' English proficiency levels are low, particularly in reading, as shown by many researchers (Chomchaiya, 2014; Hayikaleng et al., 2016; Kasemsap \& Lee, 2015; Noom-Ura, 2013; Sawangsamutchai \& Rattanavich, 2016). Reading is a necessary skill for those seeking knowledge; importantly, for Engineering students some Engineering textbooks are written in English while the medium of instruction is Thai, and most Engineering knowledge derives from other sources such as journals published in English and the Internet. These students thus need reading skills in English for their studies and future careers. Deficiency in the ability to read English may affect their success at university and their future careers which, at present, mostly use English as the principal medium. Consequently, it is interesting to reveal the contributory factors and problems affecting students of Industrial and Electrical Engineering at Rajamangala University of Technology Lanna (RMUTL) Tak in regard to their ability to read English journals. The findings from this study are expected to become very useful regarding improvement in both learning and teaching of reading by applying the appropriate reading materials, pedagogy, and classroom management that can help enhance students' reading skills.

\subsection{Objectives of the Study}

1. To examine the most significant contributory factors affecting ability of Engineering students' at RMUTL Tak to read English language journals.

2. To investigate problems with the reading ability of students at RMUTL Tak.

These are the reasons that students cannot read efficiency and may represent a problem for them in the future.

Reading is therefore a skill that students want to acquire and is essential in regard to their graduating and for their future careers.

\section{Literature Review}

Reading is a skill that Engineering students need to acquire for their education and future careers. In particular, most textbooks and journal articles for undergraduate students are challenging in many ways and students have to obtain knowledge in the Engineering field from various sources that are mostly published in international journals using English as the medium. Certainly, Engineering students have to read those and learners face difficulties or problems influencing their comprehension when they read the journals.

Contributory factors to difficulty in reading texts can arise from various elements within the text, the knowledge base of the individual reader, or the context of an interaction between writer and reader. Within the text lie unfamiliar vocabulary, complicated sentence structure as well as the organizational pattern. The individual reader approaches the same piece of text with variation in background knowledge, reading proficiency, and purpose (Nuttall, 2000). Factors that affect reading include, but are not limited to, the rate of comprehension and retention, bad spelling, hyperactivity, poor self-esteem, and lack of coping skills. Intellectual and developmental learning disabilities are often seen in students while learning how to read, and symptoms progressively worsen without appropriate resources. There are the factors that impact learners' reading comprehension, including vocabulary knowledge, prior 
knowledge, metacognitive information, reading strategies, reading attitude, useful teaching of comprehension methods, versatility, text structure, awareness of various reading comprehension sentences, working memory, anxiety, motivation to read, and interests (Coady, 1979; Koda, 2007; Meniado, 2016; Nergis, 2013; Perfetti, Landi, \& Oakhill, 2005; Trehearne \& Doctorow, 2005).

Many Thai English as a foreign language (EFL) Engineering students, in particular, have encountered problems in reading English, with limited vocabulary and sentence structure regarded as the main problems. Various authors (Gunning, 2002; Hayes, 1991; and Kinzer \& Lue, 1995) have claimed that knowledge of vocabulary is very important in facilitating students' understanding of complex materials - for example, textbooks or journals that contain concepts and technical vocabulary. In terms of vocabulary, this is associated with difficulties such as technical terms, synonyms, antonyms, and words with several meanings (Carlisle, 2000; Nuttall, 2000; Vilenius-Tuohimaa, Aunola, $\&$ Nurmi, 2008). In regard to sentence structure, those that are very long and complex cause problems in reading for Thai EFL students as well. Moreover, Nuttall (2000) stated that "complex noun groups, nominalization, coordinating conjunctions, participial phrases, and prepositional phrases are the main causes of problems in reading comprehension of the students because they render texts complex and difficult to understand". It is obvious that word difficulty and complex sentence structure can create a reading problem for Thai EFL undergraduate students if their lack of knowledge of these two areas impedes their reading ability.

Additionally, Norton \& Wolf (2012) and Kirby, Georgiou, Martinussen, \& Parrila (2010) stated that "reading problems or reading difficulties can be performed in many aspects of concurrent and future reading ability (word reading and text comprehension, accuracy and fluency) in typically developing readers and those with reading difficulties." Figure 1 shows that there are three common patterns of poor reading ability involving specific wordreading difficulties (SWRD), specific reading comprehension difficulties (SRCD), and mixed reading difficulties (MRD) (Spear-Swerling, 2016). So, when a student is faced with these problems, they affect reading ability as well.

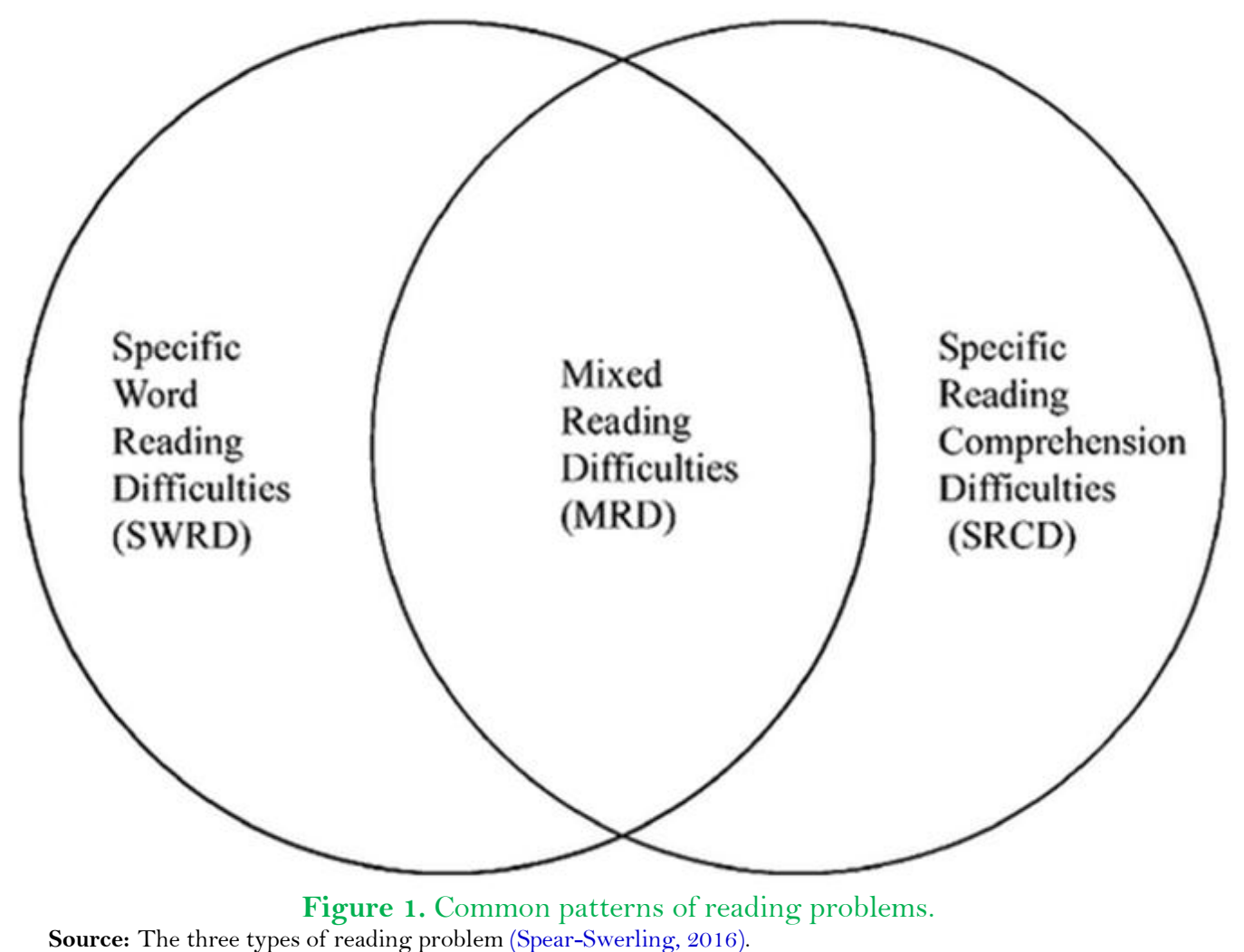

Several studies are related to the factors and problems affecting reading. A study by Al-Jarrah and Ismail (2018) investigated reading comprehension difficulties among EFL learners in higher learning institutions. Their findings revealed that the major difficulty faced by Arab EFL learners is the inability to recognize types of text. This study concluded that reading comprehension difficulties faced by Arab EFL learners in the selected institutions could affect their English language proficiency and academic performance. To find solutions to these difficulties, there is a need for shared efforts among English language teachers, instruction policymakers, public and private bodies responsible for educational policy learning and implementation, and EFL learners.

Gilakjani \& Sabouri (2016) studied the factors affecting EFL learners' reading comprehension skills and strategies for improvement. Reading comprehension is a significant skill helping the student in decoding a text, and in analyzing, explaining, and expressing their ideas about written material. The learner should develop a strong ability to understand written materials in order to cope with the academic task presented by their teachers. The purpose of this study was to aid learners in improving their skills and comprehension of texts if they want to become accomplished readers of English. The findings indicated that appropriate reading strategies play a vital role in improving EFL learners' reading skills.

Tánczikné (2017) researched factors affecting reading comprehension, intending to tap into the processes of comprehension to determine how people read. This study discussed factors influencing reading comprehension. The findings demonstrated that the student needs systematic phonological and morphological training to become a good reader. Reading abilities develop over time, readers gradually realized that meaning was often more complex than a single word, a sentence, or even a paragraph, and, in the end, they learned how to read between the lines by association. They must use their background knowledge to make the inference, which is necessary to reveal the deeper meaning.

Kulesz, Francis, Barnes, \& Fletcher (2016) examined the influence of properties of the test and their interactions with reader characteristics on reading comprehension: an explanatory item response study. This study undertook 
research including integration using the reading comprehension subtest of the Gates-MacGinitie Reading Test, investigating characteristics of the test's reading passages and comprehension questions, and the component reading skills of students in middle and high school, to determine the extent to which each of these dimensions affects test performance, both on average and through interaction with one another. The components skills of reading included word reading, reading fluency, vocabulary, background knowledge, and working memory. It was found that better vocabulary and background knowledge were the most important characteristics in accounting for reading comprehension.

To sum up, the literature review demonstrates that factors such as knowledge of vocabulary, background or prior knowledge, reading strategies, sentence structure working memory, anxiety, motivation to read, and interests determine students' reading of English language journals. It is also believed that once both learners and teachers have recognized the factors and problems affecting reading ability, this will improve. Hence, this study aims to examine the most significant contributory factors and problems affecting the ability of Engineering students at RMUTL Tak to read English journals.

\section{Research Methodology}

This section contains an explanation of the research process which covers research type, research tools, participants, and data collection procedures. It was a quantitative study, with an open and close-ended questionnaire applied to collect data.

\subsection{Participants}

The participants in this study were selected using a purposive sampling method. They were 60 Engineering students majoring in the Electrical Engineering and Industrial Engineering Program at the Faculty of Engineering at RMUTL Tak. The reason for choosing Electrical and Industrial Engineering students was because they had experience in and were assigned to reading English journals. Moreover, they had to present what they had read in front of their class. Therefore, the participants were appropriate to the research objective of answering the research questions to discover the most significant factors affecting their reading of English language journals, and to reveal the problems that students encounter while reading English journals.

\subsection{Research Questions}

1. What are the most significant contributory factors that affect the ability of Engineering students at RMUTL Tak to read English language journals?

2. What are the problems that students encounter when they read English language journals?

\subsection{Research Instruments}

In regard to the contributory factors affecting the ability to read English journals, a survey-questionnaire was employed for this study which was divided into three parts to collect the necessary data: general information, factors affecting reading, and problems occurring during reading of English journals.

Part I comprised five general information items about gender, age, duration of learning English, reading English, and experience of reading in English.

Part II was a questionnaire designed within the rating scale format. There were nine items about factors affecting reading of journals in English, including attitude, vocabulary, sentences, and motivation. The questionnaire in this study was designed using a five-point Likert scale: $5=$ very high, $4=$ high, $3=$ average, $2=$ low, $1=$ very low.

Part III included one item, an open-ended question, to indicate the problems encountered by participants in reading English journals.

\subsection{Data Collection and Analysis}

The participants were requested to fill in the questionnaire individually, and the data were collected once only. The quantitative data derived from the questionnaires, which were delivered to 20 students in the trial, served as the pilot study. Table 1 shows that the data regarding the reliability of the questionnaire were trained through the alpha coefficient (Cronbach's alpha coefficient, 0.786) using the SPSS program version 16.

\section{veliability. \\ Reliability statistics}

\begin{tabular}{c|c}
\hline Cronbach's alpha & Items $(\boldsymbol{n})$ \\
\hline 0.786 & 14 \\
\hline Source: The pilot study was calculated from SPSS version 16
\end{tabular}

This was deemed acceptable also for internal consistency, according to Table 2:

\begin{tabular}{c|l}
\hline \multicolumn{2}{c}{ Table 2. Cronbach's alpha coefficient for internal consistency. } \\
\hline Cronbach's alpha & Internal consistency \\
\hline $0.9 \leq \alpha$ & Excellent \\
\hline $0.8 \leq \alpha<0.9$ & Good \\
\hline $0.7 \leq \alpha<0.8$ & Acceptable \\
\hline $0.6 \leq \alpha<0.7$ & Questionable \\
\hline $0.5 \leq \alpha<0.6$ & Poor \\
\hline$\alpha<0.5$ & Unacceptable \\
\hline Source: Cronbach's alpha coefficient for internal consistency (George \& Mallery, 2003).
\end{tabular}

Next, the data were analyzed using a statistical computer program with mean and standard deviation (SD) for each item. Finally, the results were interpreted and summarized. 


\subsection{Methods of Data Analysis}

The quantitative data derived from 60 questionnaires were gathered. Afterwards, they were collated and analyzed for mean or average $(\bar{x})$ and SD using SPSS program version 16, and the Microsoft Excel Program to create diagrams. Mean score interpretation is shown in Table 3:

\begin{tabular}{c|l}
\hline \multicolumn{2}{c}{ Table 3. Mean score interpretation (Moidunny, 2009). } \\
\hline Mean score & Interpretation \\
\hline $4.21-5.00$ & Very high \\
\hline $3.21-4.20$ & High \\
\hline $2.61-3.20$ & Medium \\
\hline $1.81-2.60$ & Low \\
\hline $1.00-1.80$ & Very low \\
\hline Source: Mean score interpretation table (Moidunny, 2009).
\end{tabular}

Additionally, a $t$-test was applied to compare results between two groups of respondents and to reveal the differences and similarities affecting undergraduate students' ability in reading English journals.

The data in Part III included only one item, which was an open-ended question. This was conducted to explore the problems faced by the participant; by applying 'Grounded theory' using open coding to break down and categorize the data (Strauss \& Cirbin, 1998) as colored coding and then using the frequency distribution $(f)$ in the answer, these were calculated to indicate the problems encountered while reading.

\section{Results}

The factors and problems affecting undergraduate students' ability in reading English journals were examined by applying quantitative data and analyzed using a statistical computer program to answer two research questions.

A pilot study for this study was implemented in RMUTL Tak, to measure the reliability of the research instrument and the acceptability of the overall questionnaire, with Cronbach's alpha (0.786).

For the actual research, the response rate for answering the questionnaires was $100 \%-60$ students from two majors of the Faculty of Engineering responded. Descriptive analysis was carried out using a statistical computer program to show the mean and SD, and Microsoft Excel to create the images.

\subsection{Answer to Research Question 1}

4.1.1. Contributory Factors that Affect Industrial Engineering Students' Ability to Read English Journals.

The data from Table 4 indicate the mean and SD for each factor (Moidunny, 2009) affecting Industrial Engineering students' ability in reading English journals, and show the contributory factors at a high level.

\begin{tabular}{l|l|l|l|l|l}
\hline Table 4. Mean, SD, and significance levels of factors affecting Industrial Engineering students' ability to read English journals. \\
\hline Item & Factor & Mean & SD & $\begin{array}{l}\text { Significance } \\
\text { level }\end{array}$ & Range \\
\hline 1. & Attitudes towards reading English journals & 4.30 & 0.466 & Very high & 4 \\
\hline 2. & Knowledge of vocabulary & 4.20 & 0.407 & High & 6 \\
\hline 3. & Sentences are complex and very long & 4.23 & 0.430 & Very high & 5 \\
\hline 4. & Anxiety in regard to reading English journals & 4.90 & 0.305 & Very high & 1 \\
\hline 5. & $\begin{array}{l}\text { Ability to memorize the vocabulary and content proves } \\
\text { too difficult in regard to reading English journals }\end{array}$ & 4.53 & 0.681 & Very high & 3 \\
\hline 6. & Strategies in reading English journals & 3.10 & 0.305 & Medium & 8 \\
\hline 7. & Prior knowledge of the English language & 3.23 & 0.430 & High & 7 \\
\hline 8. & Motivation to read English journals & 4.60 & 0.621 & Very high & 2 \\
\hline 9. & Attractive content for reading journals in English & 3.00 & 0.000 & Medium & 9 \\
\hline Total & & 4.01 & 0.405 & High & \\
\hline Source: 30 Industrial Engineering students from RMUTL Tak & & &
\end{tabular}

Source: 30 Industrial Engineering students from RMUTL Tak.

Mean and SD were divided into nine factors affecting Industrial Engineering students' ability in reading English journals; the overview factors affecting their ability were at the high level $(\bar{x}=4.01)$. Table 4 shows that anxiety about reading English journals (item 4) was the outstanding factor affecting the students' ability in reading English journals $(\bar{x}=4.90$ ) which was in the first range. On the other hand, item 9 (attractive content for reading journals in English) was at the lowest level $(\bar{x}=3.00)$ which was in the ninth range. With regard to the other ranges of the factors affecting Industrial Engineering students' ability in reading English journals, it revealed that the second range was item 8 , motivation to read English journals $(\bar{x}=4.60)$. Next, ability to memorize the vocabulary and content proves too difficult in regard to reading English journals (item 5) was in the third range $(\bar{x}=4.53$ ). Meanwhile, item 1, attitudes towards reading English journals $(\bar{x}=4.30)$, item 3, sentences are complex and very long $(\bar{x}=4.23)$, item 2 , knowledge of vocabulary $(\bar{x}=4.20)$, item 7 , prior knowledge of the English language $(\bar{x}=$ 3.23), and item 6, strategies in reading English journals $(\bar{x}=3.10)$, they were the fourth to eighth range, respectively.

\subsubsection{Contributory Factors Affecting Electrical Engineering Students' Ability to Read English Journals}

The data from Table 5 indicate the mean and SD for each contributory factor (Moidunny, 2009), at a high level, affecting Electrical Engineering students' ability to read English journals. 
Table5. Mean, SD, and significance levels of factors affecting Electrical Engineering students' ability to read English journals.

\begin{tabular}{|c|c|c|c|c|c|}
\hline Item & Factor & Mean & SD & $\begin{array}{l}\text { Significance } \\
\text { level }\end{array}$ & Range \\
\hline 1. & Attitudes towards reading English journals & 4.10 & 0.305 & High & 4 \\
\hline 2. & Knowledge of vocabulary & 4.77 & 0.430 & Very high & 1 \\
\hline 3. & Sentences are complex and very long & 3.87 & 0.681 & High & 5 \\
\hline 4. & Anxiety in regard to reading English journals & 3.80 & 0.761 & High & 6 \\
\hline 5. & $\begin{array}{l}\text { Ability to memorize vocabulary and the content is too difficult } \\
\text { in regard to reading English journals }\end{array}$ & 4.43 & 0.568 & Very high & 3 \\
\hline 6. & Strategies in reading English journals & 3.10 & 0.305 & Medium & 7 \\
\hline 7. & Prior knowledge of the English language & 3.80 & 0.847 & High & 6 \\
\hline 8. & Motivation to read English journals & 4.60 & 0.563 & Very high & 2 \\
\hline 9. & Attractive content for reading journals in English & 3.07 & 0.254 & Medium & 8 \\
\hline Total & & 3.95 & 0.524 & \multicolumn{2}{|l|}{ High } \\
\hline
\end{tabular}

Source: 30 Electrical Engineering students from RMUTL Tak.

Mean and SD were divided into nine items, which were the factors affecting Electrical Engineering students' ability in reading English journals, and the overview factors affecting their ability were at the high level $(\bar{x}=3.95)$. Table 5 shows that item 2 , knowledge of vocabulary was the outstanding contributory factor affecting Electrical Engineering students' ability in reading English journals $(\bar{x}=4.77)$ which was in the first range , whereas item 9, attractive content for reading journals in English was the lowest $(\bar{x}=3.07)$ which was in the eighth range. In addition, it was presented that the second range of the contributory factor affecting Electrical Engineering students ability was item 8, motivation to read English journals $(\bar{x}=4.60)$. The third range was item 5 , ability to memorize the vocabulary and content proves too difficult in regard to reading English journals $(\bar{x}=4.43)$. While item 1, attitudes towards reading English journals and item 3, sentences are complex and very long were in the fourth $(\bar{x}=$ 4.10) and the fifth range $(\bar{x}=3.87)$ whereas item 4, anxiety in regard to reading English journals and item 7, prior knowledge of the English language were in the sixth range $(\bar{x}=3.80)$ equally. Item 6, strategies in reading English journals was the seventh range $(\bar{x}=3.10)$ which affecting students' ability to read English journals, respectively.

4.1.3. Comparison of Contributory Factors Affecting Undergraduate Students' Ability in Reading English Journals

The data from Table 6 present differences and similarities in contributory factors affecting undergraduate students' abilities in reading English journals between two groups of the participants majoring in Industrial and Electrical Engineering at RMUTL Tak.

\begin{tabular}{|c|c|c|c|c|c|c|}
\hline Factor & Major & $n^{1}$ & $\overline{\boldsymbol{x}}^{2}$ & $\mathbf{S D}^{3}$ & $T$ & Sig. ${ }^{5}$ \\
\hline \multirow{2}{*}{ 1. Attitudes towards reading English journals } & Industrial & 30 & 4.30 & 0.466 & \multirow{2}{*}{1.966} & 0.54 \\
\hline & Electrical & 30 & 4.10 & 0.305 & & 0.55 \\
\hline \multirow{2}{*}{ 2. Knowledge of vocabulary } & Industrial & 30 & 4.20 & 0.407 & \multirow{2}{*}{-5.242} & \multirow{2}{*}{$0.000^{*}$} \\
\hline & Electrical & 30 & 4.77 & 0.430 & & \\
\hline \multirow{2}{*}{ 3. Sentences are complex and very long } & Industrial & 30 & 4.23 & 0.430 & \multirow{2}{*}{2.492} & \multirow{2}{*}{0.16} \\
\hline & Electrical & 30 & 3.87 & 0.681 & & \\
\hline \multirow{2}{*}{ 4. Anxiety in regard to reading English journals } & Industrial & 30 & 4.90 & 0.305 & \multirow{2}{*}{7.347} & \multirow{2}{*}{$0.000^{*}$} \\
\hline & Electrical & 30 & 3.80 & 0.761 & & \\
\hline \multirow{2}{*}{$\begin{array}{l}\text { 5. Ability to memorize vocabulary and content inadequate for } \\
\text { reading English journals }\end{array}$} & Industrial & 30 & 4.53 & 0.681 & \multirow{2}{*}{0.617} & 0.539 \\
\hline & Electrical & 30 & 4.43 & 0.568 & & 0.540 \\
\hline \multirow{2}{*}{ 6. Strategies in reading English journals } & Industrial & 30 & 3.10 & 0.305 & \multirow{2}{*}{0.000} & \multirow{2}{*}{1.000} \\
\hline & Electrical & 30 & 3.10 & 0.305 & & \\
\hline \multirow{2}{*}{ 7. Prior knowledge of the English language } & Industrial & 30 & 3.23 & 0.430 & \multirow{2}{*}{-3.267} & \multirow{2}{*}{$0.002 *$} \\
\hline & Electrical & 30 & 3.80 & 0.847 & & \\
\hline \multirow{2}{*}{ 8. Motivation to read English journals } & Industrial & 30 & 4.60 & 0.621 & \multirow{2}{*}{0.000} & \multirow{2}{*}{1.000} \\
\hline & Electrical & 30 & 4.60 & 0.563 & & \\
\hline \multirow{2}{*}{ 9. Attractive content for reading journals in English } & Industrial & 30 & 3.00 & 0.000 & \multirow{2}{*}{-1.439} & 0.155 \\
\hline & Electrical & 30 & 3.07 & 0.000 & & 0.161 \\
\hline
\end{tabular}

* Note: Statistical significance level $=0.05$

Table 6 and Figure 2 present analysis of the differences and similarities in factors affecting Engineering undergraduate students' abilities in reading English journals and who have studied at RMUTL Tak, clustered according to their major (Industrial or Electrical Engineering) by applying $t$-testing to analyze the results. It was revealed that students in both majors recognized that the factors affecting their reading ability were both different and similar to the significance of each factor. According to the significance value from the testing, it was demonstrated that the difference in mean value was statistically significant at 0.05 regarding the following categories: knowledge of vocabulary $(\bar{x}=4.22,4.77)$; anxiety in reading English journals $(\bar{x}=4.90,3.80)$; and prior knowledge about the English language $(\bar{x}=3.23,3.80)$, with a significance value of $>0.05$.

Nevertheless, the following categories had no statistical significance at 0.05 because the significance value was $>0.05$ : attitudes towards reading English journals $(\bar{x}=4.30,4.10)$; sentences are complex and very long $(\bar{x}=4.23$, 3.87 ); ability to memorize vocabulary and content is too difficult for reading English journals $(\bar{x}=4.53,4.43)$; and attractive content for reading journals in English $(\bar{x}=3.00,3.07)$.

${ }^{1} n=$ sample size, ${ }^{2} \overline{\mathrm{x}}=$ mean value, ${ }^{3} \mathrm{SD}=$ standard deviation, ${ }^{4} T=t$-test statistic, ${ }^{5} \mathrm{Sig} .=$ significant level. 
Analysis of differences and similarities in factors

affecting undergraduate students' ability in reading English journals

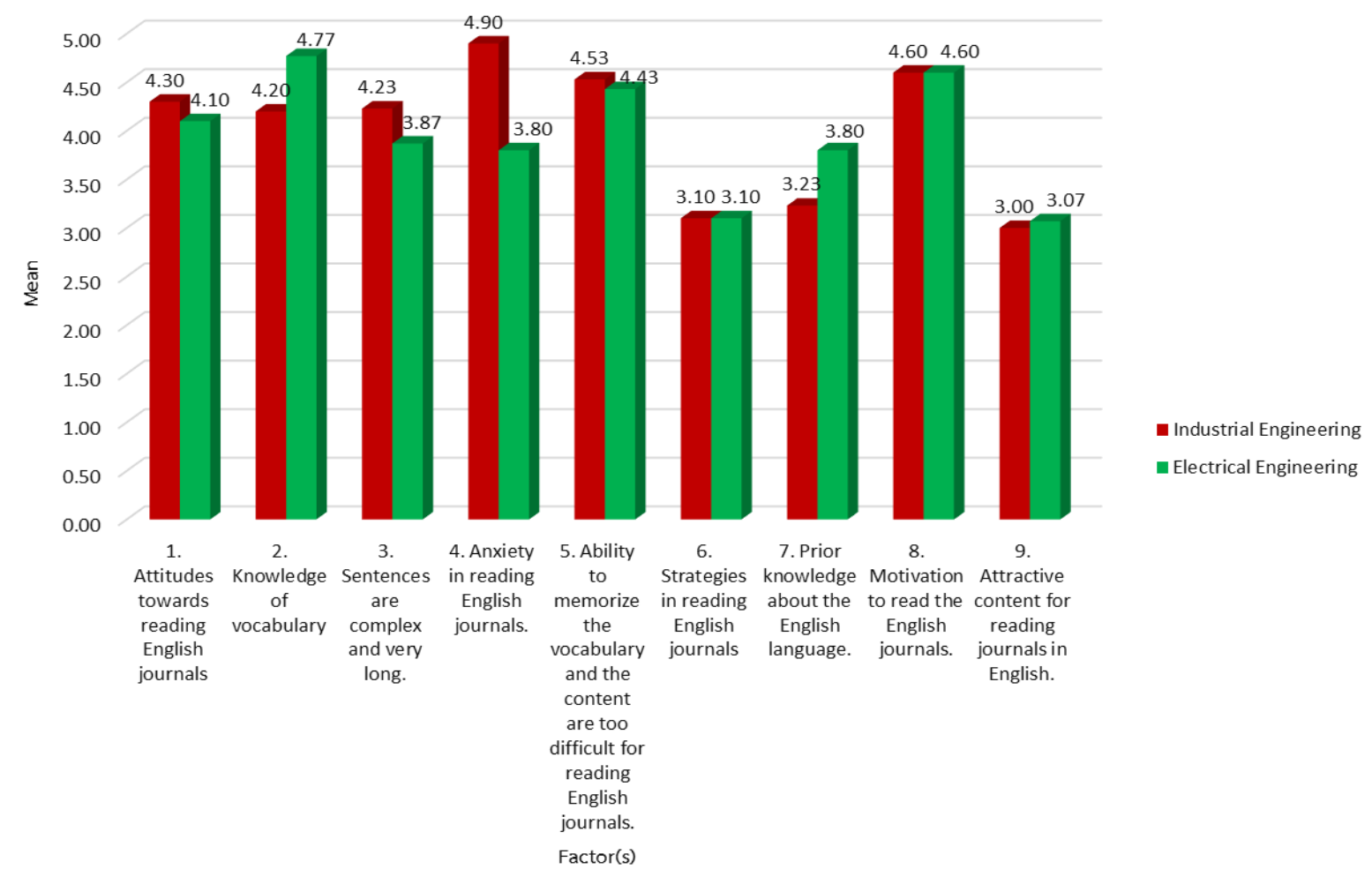

Figure 2. Analysis of differences and similarities in factors affecting undergraduate students' ability in reading English journals Source: 30 Industrial Engineering and 30 Electrical Engineering students from RMUTL Tak.

On the other hand, in the following categories no differences were found in the mean value that were statistically significant at 0.05: strategies in reading English journals $(\bar{x}=3.10,3.10)$ and motivation to read English journals $(\bar{x}$ $=4.60,4.60)$,

\subsection{Answer to Research Question 2}

4.2.1. Problems Encountered by Industrial Engineering Students in Reading English Journals

The results show that the problems encountered by the respondents when they read English journals were clustered into seven problems and, by categorization of the data (Strauss \& Cirbin, 1998) as colored coding and then using the frequency distribution $(f)$ in the answer, they were calculated to indicate the problems encountered. These were (1) vocabulary is too difficult $(f=30)$; (2) journals are difficult $(f=29)$; (3) unable to translate $(f=27)$; (4) too lazy to read $(f=23) ;(5)$ misunderstanding the content $(f=21)$; (6) students not interested in reading $(f=15)$; and (7) journals have too many pages $(f=9)$, as shown in Figure 3.

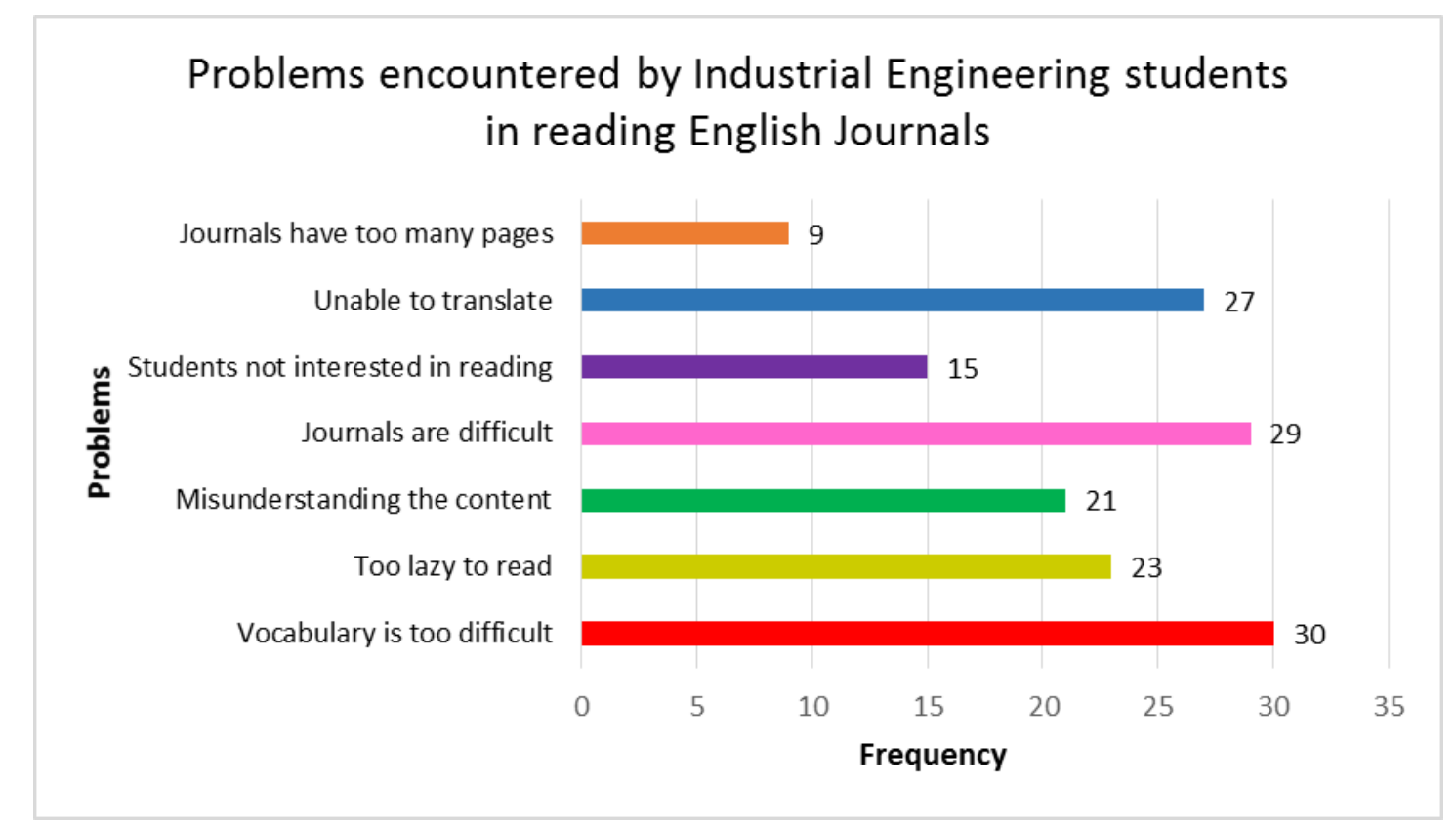

Figure 3. Problems encountered by Industrial Engineering students in reading English journals. Source: 30 Industrial Engineering students from RMUTL Tak.

\subsubsection{Problems Encountered by Electrical Engineering Students in Reading English Journals}

The results indicated that the problems encountered by respondents when reading English journals could be clustered into eight groups, categorizing the data (Strauss \& Cirbin, 1998) by color coding and then using the frequency distribution $(f)$ in the answer; they were calculated to indicate the problems encountered while reading: (1) vocabulary is too difficult $(f=29)$; (2) journals are difficult $(f=27) ;(3)$ misunderstanding the content $(f=20) ;(4)$ too 
lazy to read $(f=19)$; (5) journals have too many pages $(f=17) ;(6)$ student not interested in reading $(f=16) ;(7)$ unable to translate $(f=11)$; and $(8)$ content not related to that previously learned $(f=7)$ (Figure 4).

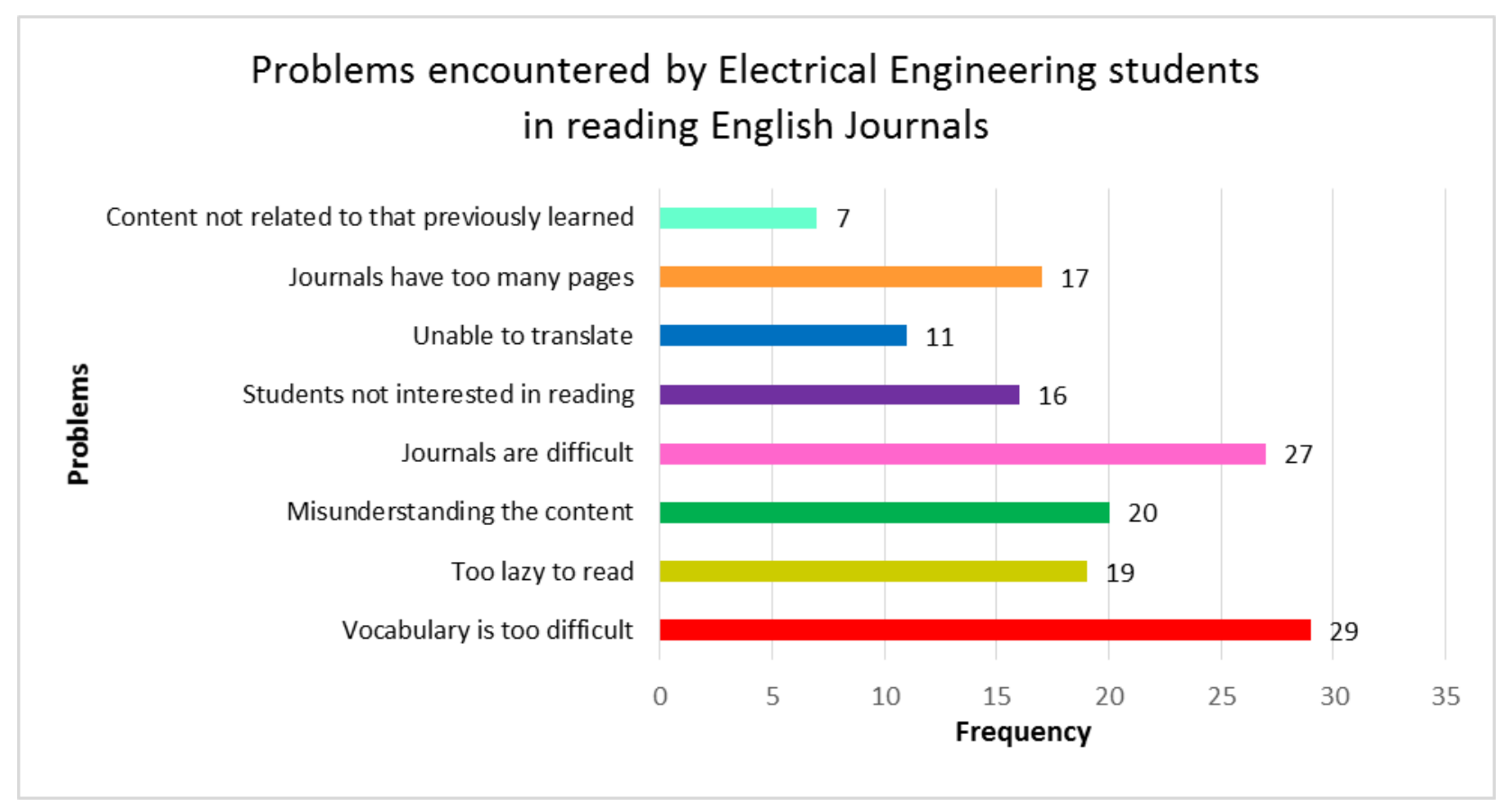

Figure 4. Problems encountered by Electrical Engineering students in reading English journals. Source: 30 Electrical Engineering students from RMUTL Tak.

\subsubsection{Comparison of Problems Encountered by Undergraduate Students in Reading English Journals}

The findings from the questionnaires revealed that Industrial and Electrical Engineering students encountered many problems: (1) vocabulary is too difficult $(f=30,29)$; (2) too lazy to read $(f=23,19)$; (3) misunderstanding the content $(f=21,20)$; (4) journals are difficult $(f=29,27)$; (5) student not interested in reading $(f=15,16)$; $(6)$ unable to translate $(f=27,11)$; and $(7)$ journals have too many pages $(f=9,17)$, as shown in Figure 5 . Additionally, there was a further problem that occurred, specifically for Electrical Engineering students: - the content was not related to that previously learned $(f=0,7)$, as shown in Figure 5 .

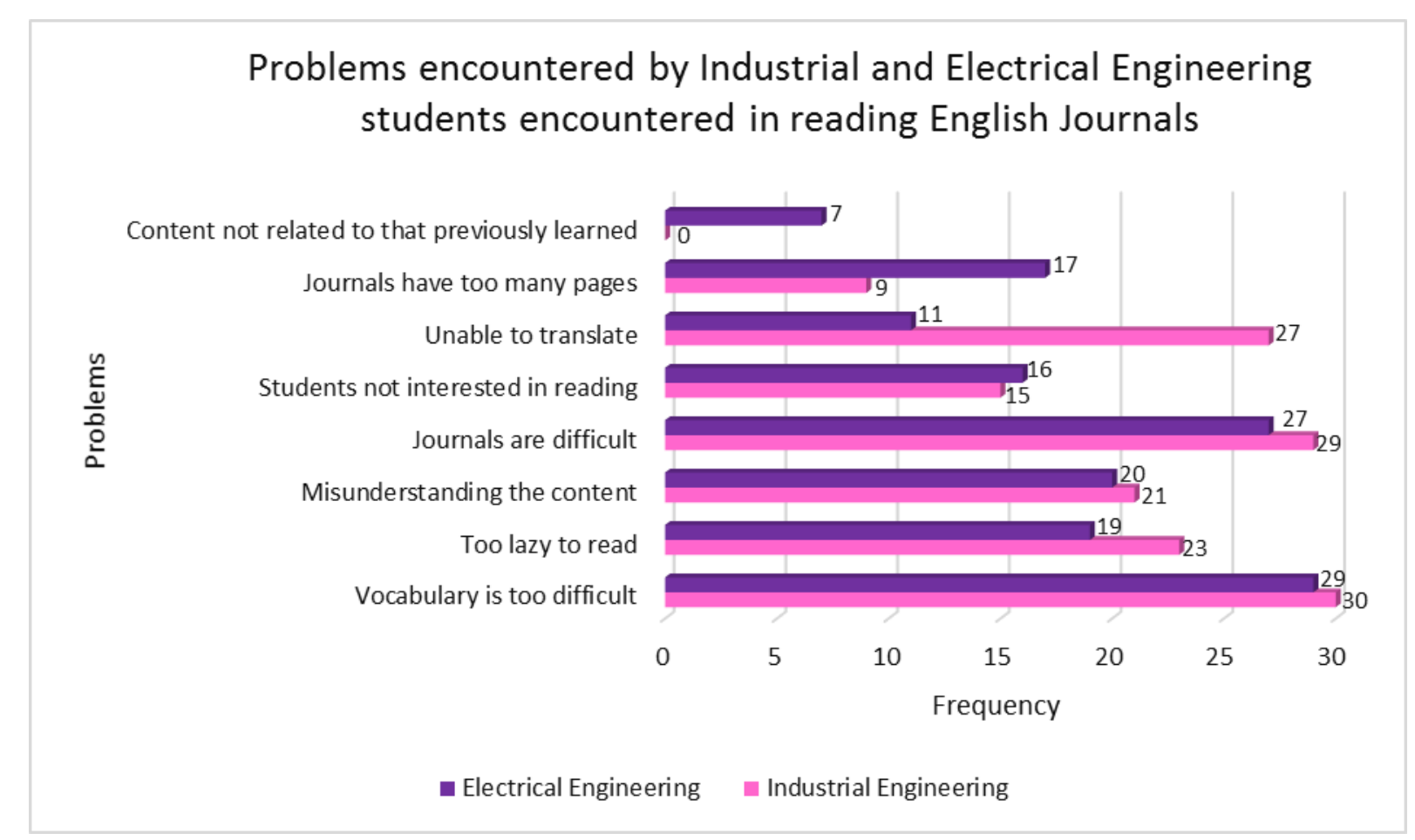

Figure 5. Problems encountered by Industrial and Electrical Engineering students in reading English journals. Source: 30 Industrial Engineering and 30 Electrical Engineering students from RMUTL Tak.

The data from Figure 5 indicated that the most common problem was that the vocabulary was too difficult for students to translate for reading and understanding the entire context of the journals, which could have been caused by the other problems mentioned. However, there was a problem that occurred with Electrical Engineering students specifically, who mentioned that the content was not related to that previously learned.

\section{Discussion}

To answer research question 1 , the results showed that the most significant contributory factor affecting Industrial Engineering students was anxiety, whereas knowledge of vocabulary was the outstanding factor affecting Electrical Engineering. Therefore, if students were unable to control their anxiety in reading English journals, this would certainly be an important factor affecting their reading. Besides, the knowledge of vocabulary was the most significant contributory factor affecting Electrical Engineering students. Tánczikné (2017) discovered that factors 
affecting and influencing reading comprehension while intending to tap into the processes of comprehension were (1) vocabulary, in which students needed systematic phonological and morphological training to become proficient readers, and (2) background knowledge, which they have to apply to make the inferences necessary to reveal more in-depth meaning. Moreover, Kulesz et al. (2016) found that better vocabulary and background knowledge were the most important characteristics in accounting for reading comprehension. Nergis (2013) investigated whether, specifically, depth of vocabulary, syntactic awareness, or metacognitive awareness was the most powerful factor in academic reading comprehension. On the other hand, these authors also discovered that complex and over-long sentences were another important contributory factor among respondents who agreed to read English journals.

Anxiety and knowledge of vocabulary were found to be the significant contributory factors that led to poor reading ability in English journals. The study of Gilakjani and Sabouri (2016) supports that decoding of skills is another factor that helps students decode a text, analyzing, explaining, and expressing their ideas about written material. The learner should develop a strong ability to understand written material in order to deal with the academic tasks set by their teachers, while appropriate reading strategies also play a vital role in improving EFL learners' reading skills.

To answer research question 2 , there were many problems encountered by students from both majors in reading English journals: (1) vocabulary is difficult; (2) unable to translate; (3) too lazy to read; (4) misunderstanding the content; (5) journals are difficult; (6) journals have too many pages; and (7) not interested in reading, which are mostly MRD from the common patterns of reading problems (Spear-Swerling, 2016). There was a specific problem mentioned by Electrical Engineering students - the content was not related to that previously learned. Consequently, the most significant contributory factors affecting English reading comprehension and problems were revealed, and are the focus for developing undergraduate students' ability to read journals through the use of appropriate reading materials, activities to enhance their reading skill both inside and outside the class, and the pedagogy and learning strategy of reading, which can improve students' reading skills to assist them in overcoming their reading problems, including classroom management, which may be fruitful for enhancing reading skills.

This study examined how the most significant contributory factors affect undergraduate students' ability to read English journals. The findings of this study will help to form guidelines for teachers to reduce students' anxiety, to increase their knowledge of vocabulary, and to avoid the problems that can occur in reading English texts, by enhancing reading skills through activities such as 'edutainment' in class and making students familiar with reading English journals, including others who are interested in developing their reading skills, because these are skills that will be preserved forever and which they can use in the future. The contributory factors affecting English reading comprehension were revealed, these being improvement in pedagogy and the learning strategy of reading, which can improve and enhance undergraduate students' reading skills to assist them in overcoming their reading problems and boost their long-term reading skills.

\section{Conclusion}

Needless to say, reading is a more important skill for students learning English around the world than are other skills, especially for those learning English as a foreign language (Grabe, 2002). It is important for them in learning and gaining knowledge from reading in English for their future, such as further studies or future careers.

From research question 1 it was revealed that the significant contributory factors affecting participants' ability to read English journals were anxiety and knowledge of vocabulary. The other factors affecting reading ability were attitudes to reading English journals; over-long and complex sentences; difficulty in memorizing vocabulary and content of English journals; strategies in English reading; prior knowledge; motivation to read English journals; and attractive content in English journals.

To answer research question 2 , the results showed that many problems were common to the two groups of undergraduate students encountered: vocabulary is difficult; unable to translate; too lazy to read; misunderstanding the content; journals are difficult; journals have too many pages; and students not interested in reading. There was a further specific problem identified by the Electrical Engineering students - the content was not related to that previously learned.

Therefore, the contributory factors affecting English reading comprehension and problems are explored, as are the solutions suggested for developing undergraduate students' ability to read journals by supplying the appropriate reading materials; using activities to enhance their reading skills both inside and outside the class; and the pedagogy and learning strategy of reading, which can develop students' reading skills to assist them in overcoming their reading problems, including classroom management, which may help enhance reading skills.

\section{References}

Al-Jarrah, H., \& Ismail, N. S. B. (2018). Reading comprehension difficulties among EFL learners in higher learning institutions. International Journal of English Linguistics, 8(7), 32-41.

Carlisle, J. F. (2000). Awareness of the structure and meaning of morphologically complex words: Impact on reading. Reading and Writing, $12(3), 169-190$.

Chomchaiya, C. (2014). An investigation into the development of English language reading comprehension among Thai undergraduate students using an online blended learning approach. Doctoral Dissertation, Curtin University.

Coady, J. (1979). A psycholinguistic model of the ESL reader. In Reading in a Second Language (Ed.), Mackay, R. et. al. Rowley: Newbury House.

Davies, P., \& Pearse, E. (2000). Success in English teaching: A complete introduction to teaching English at secondary school level and above. Oxford: Oxford University Press. United Kingdoms.

Ediger, A. (2001). Teaching children literacy skills in second language. In M. Celce-Murcia (Ed.), Teaching English as a second or foreign language (3rd ed., pp. 153-169). Boston: Heinle, Cengage Learning.

Enever, J. (2009). Can today's early language learners in England become tomorrow's plurilingual European citizens? In M. Nikolov (Ed.), Early learning of modern foreign languages: Processes and outcomes (pp. 15-29). Bristol: Multilingual Matters.

Enever., J., \& Moon, J. (2009). New global contexts for teaching primary ELT: Change and challenge. In J. Enever, J. Moon, \& U. Raman (Eds.), Young learner English language policy and implementation: International perspectives (pp. 5-21). Reading, UK: Garnet Education.

George, D., \& Mallery, P. (2003). Using SPSS for windows step by step: A simple guide and reference (4th ed.). London: Pearson Education.

Gilakjani, P. A., \& Sabouri, B. N. (2016). A study of factor affecting EFL learners' reading comprehension skill and the strategies for improvement. International Journal of English Linguistic, 6(5), 180-187. Available at: https://doi.org/10.5539/ijel.v6n5p180. 
Grabe, W. (2002). Dilemmas for the development of second language reading abilities. In J. C. Richards \& W. A. Renandya (Eds.), Methodology in language teaching (pp. 276- 286). Cambridge: Cambridge University Press.

Gunning, T. G. (2002). Assessing and correcting reading and writing difficulties. Boston: Allyn \& Bacon A Pearson Education Company.

Hayes, B. L. (1991). Effective strategies for teaching reading. Boston: Allyn and Bacon a Division of Simon \& Schuster, Inc.

Hayikaleng, N., Nair, S. M., \& Krishnasamy, H. N. (2016). Thai students' L2 reading comprehension level for lower order thinking skills and higher order thinking skills questions. Journal of Applied Linguistics and Language Research, 3(5), 83-91.

Kasemsap, B., \& Lee, H. Y.-H. (2015). L2 reading in Thailand: Vocational college students' application of reading strategies to their reading of English texts. The Reading Matrix: An International Online Journal, 15(2), 101-117.

Kinzer, C. K., \& Lue, D. J. (1995). Effective reading instruction. New Jersey: Merrill.

Kirby, J. R., Georgiou, G. K., Martinussen, R., \& Parrila, R. (2010). Naming speed and reading: From prediction to instruction. Reading Research Quarterly, 45(3), 341-362. Available at: https://doi.org/10.1598/rrq.45.3.4.

Koda, K. (2007). Readfing language learning: Cross-linguistic constrains on second language reading development. Language Learning, 57(1), 1-44. Available at: http://dx.doi.org/10.2307/747732.

Kulesz, P. A., Francis, D. J., Barnes, M. A., \& Fletcher, J. M. (2016). The influence of properties of the test and their interactions with reader characteristics on reading comprehension: An explanatory item response study. Journal of Educational Psychology, $108(8), 1078-1097$. Available at: https://doi.org/10.1037/edu0000126.

Meniado, J. C. (2016). Metacognitive reading strategies, motivation, and reading comprehension performance of Saudi EFL students. English Language Teaching, 9(3), 117-129. Available at: https://dx.doi.org/10.5539/elt.v9n3p1 17.

Moidunny, K. (2009). The effectiveness of the national professional qualifications for educational leaders (NPQEL). Unpublished Doctoral Dissertation, Bangi: The National University of Malaysia.

Nergis, A. (2013). Exploring the factors that affect reading comprehension of EAP learners. Journal of English for Academic Purposes, 12(1), 19. Available at: https://doi.org/10.1016/j.jeap.2012.09.001.

Noom-Ura, S. (2013). English-teaching problems in Thailand and Thai teachers' professional development needs. English Language Teaching, 6(11), 139-147. Available at: https://doi.org/10.5539/elt.v6n11p139.

Norton, E. S., \& Wolf, M. (2012). Rapid automatized naming (RAN) and reading fluency: Implications for understanding and treatment of reading disabilities. Annual Review of Psychology, 63(1), 427-452. Available at: https://doi.org/10.1146/annurev-psych-120710100431 .

Nuttall, C. (2000). Teaching reading skills in a foreign language. Heinemann: MacMillan.

Perfetti, C. A., Landi, N., \& Oakhill, J. (2005). The acquisition of reading comprehension skill. In M. J. Snowling \& C. Hulme (Eds.), Blackwell handbooks of developmental psychology. The science of reading: A handbook (pp. 227-247): Blackwell Publishing.

Sawangsamutchai, Y., \& Rattanavich, S. (2016). A comparison of seventh grade thai students' reading comprehension and motivation to read English through applied instruction based on the genre-based approach and the teacher's manual. English Language Teaching, 9(4), 54-63.

Spear-Swerling, L. (2016). Common types of reading problems and how to help children who have them. The Reading Teacher, 69(5), $513-522$. Available at: https://doi.org/10.1002/trtr.1410.

Strauss, A., \& Cirbin, J. (1998). Basics of qualitative research: Techniques and procedures for developing grounded theory (2nd ed.). Thousand Oaks, CA: SAGE Publications, Inc.

Tánczikné, V. S. (2017). Factor affecting reading comprehension. Gradus, 4(2), 41-47.

Trehearne, M., \& Doctorow, R. (2005). Reading comprehension: Strategies that work. Comprehensive Literacy Resource: Grade, 3-6(Chapter 2), $97-186$.

Ur, P. (1996). A course in language teaching. Practice and theory. Cambridge: Cambridge University Press.

Vilenius-Tuohimaa, P. M., Aunola, K., \& Nurmi, J.-E. (2008). The association between mathematical word problems and reading comprehension. Educational Psychology, 28(4), 409-426. Available at: https://doi.org/10.1080/01443410701708228.

Wutthisingchai, S., \& Stopps, J. P. (2018). An analysis of factors affecting the english reading comprehension of Mattayomsuksa 5 students in Amphur Mueang, Lammpang Province. The New English Teacher, 12(2), 32-58. 